\title{
FAKTOR RISIKO CARPAL TUNNEL SYNDROME PADA SISWA SEKOLAH MENENGAH ATAS PEMAIN GAME ONLINE DI KOTA DENPASAR
}

\author{
Ni Luh Made Susanthi Pramandani, I Made Ady Wirawan* \\ Program Studi Kesehatan Masyarakat Fakultas Kedokteran Universitas Udayana \\ *email: ady.wirawan@unud.ac.id
}

\begin{abstract}
ABSTRAK
Carpal Tunnel Syndrome (CTS) merupakan salah satu gangguan pada lengan tangan akibat penyempitan terowongan karpal sehingga terjadi penekanan terhadap nervus medianus. Gerakan tangan saat menggunakan keyboard dan mouse dalam bermain game online memiliki tingkat repetisi tinggi pada jari tangan sehingga dapat berpengaruh terhadap kejadian CTS. Penelitian ini bertujuan untuk mengetahui proporsi dan faktor risiko CTS pada siswa SMA pemain game online di Kota Denpasar. Penelitian kuantitatif analitik dengan rancangan cross-sectional study. Responden berjumlah 70 siswa dengan teknik pengambilan sampel purposive sampling. Hasil menunjukan proporsi CTS responden sebesar 31,43\% dengan kategori ringan. Seluruh variabel karakteristik individu yang mencakup usia $(p=0,25)$ dan jenis kelamin $(p=0,50)$ tidak memiliki hubungan yang bermakna dengan kejadian CTS, sedangkan variabel pola bermain, perangkat bermain, dan repetitive motion $(p=0,00)$ terbukti memiliki hubungan bermakna dengan kejadian CTS. Pola bermain merupakan faktor risiko yang paling berpengaruh terhadap kejadian CTS pada siswa pemain game online dengan $\mathrm{OR}=23,74$. Oleh karena itu diperlukan adanya dukungan pemerintah berupa program preventif - rehabilitatif bagi pecandu game untuk mengedukasi siswa dan orangtua terkait dampak game online.
\end{abstract}

Kata Kunci: Carpal Tunnel Syndrome, Siswa, Game Online

\begin{abstract}
Carpal Tunnel Syndrome (CTS) is one of the disorders in the arm of the hand due to the narrowing of the carpal tunnel so that it occurs with an emphasis on the median nerve. Hand movements when using the keyboard and mouse in playing online games have a high repetition rate that affect the incidence of CTS. This research aimed to determine proportion and risk factors of CTS experienced by senior high students who playing game online in Denpasar city, using quantitative analytic research with cross-sectional study design. Respondents in this study amounted to 70 students with purposive sampling technique. The results showing CTS proportion of respondents at $31.43 \%$ in mild category. All individual characteristic variables including age $(p=0.25)$ and gender $(p=0.50)$ are not significantly related to CTS, while playing patterns, playing devices, and repetitive motion $(p=0.00)$ are significantly related with CTS incidence. Playing patterns are the most influential risk factor of CTS incident in senior high students who play online game $(\mathrm{OR}=23.74)$. Therefore government support in preventive - rehabilitative program for gamers addicted is necessary to educate students and their parents about game online's impact.
\end{abstract}

Keywords: Carpal Tunnel Syndrome, Students, Game Online

\section{PENDAHULUAN}

Pada era globalisasi saat ini, penguasaan teknologi menjadi prestise dan indikator kemajuan suatu negara (Ngafifi, 2014). Kemajuan teknologi adalah sesuatu yang tidak bisa dihindari dalam kehidupan ini, karena kemajuan teknologi akan berjalan sesuai dengan kemajuan ilmu pengetahuan. Setiap inovasi teknologi yang diciptakan dapat memberikan manfaat positif bagi kehidupan manusia (Ngafifi, 2014). Salah satu hasil dari perkembangan teknologi adalah internet (Kusumawardani, 2015).

Berdasarkan hasil survey Asosiasi Penyelenggara Jasa Internet Indonesia, 
sebanyak $64,8 \%$ atau sekitar 171,17 juta jiwa penduduk Indonesia menggunakan internet (APJII, 2019). Teknologi internet saat ini tidak hanya digunakan untuk memenuhi kebutuhan informasi namun juga pada halhal yang bersifat hiburan (entertainment). Salah satu hiburan yang banyak mendapat perhatian dari masyarakat adalah game online (Fajri, 2012).

Indonesia menjadi salah satu dari 20 negara tujuan pengakses game online terbanyak. Berdasarkan data Asosiasi Penyelenggara Jasa Internet Indonesia pada tahun 2019 diketahui sebanyak 54,13\% penduduk Indonesia menggunakan internet untuk bermain game (APJII, 2019). Salah satu pengguna internet untuk bermain game secara online adalah remaja. Menurut Oblinger \& Oblinger (2005) remaja disebut generasi post-millenials yang salah satu cirinya yaitu tumbuh dengan teknologi yang sangat mudah untuk diakses. Remaja dianggap lebih sering dan lebih rentan terhadap kecanduan game online daripada orang dewasa. Masa remaja yang berada pada periode ketidakstabilan, cenderung lebih mudah terjerumus terhadap percobaan hal-hal baru (Jordan \& Andersen, 2017).

Bermain game online dapat memberikan dampak positif maupun dampak negatif bagi remaja. Dampak positif bermain game online yaitu mampu menjadi sarana hiburan atau media penyegaran otak dikala merasa frustasi dan kelelahan akibat kegiatan belajar yang telah dilalui (Eskasasnanda, 2017). Sedangkan, dampak negatif yang diakibatkan oleh kecanduan game online yaitu remaja cenderung kurang tertarik terhadap kegiatan lain, merasa gelisah saat tidak dapat bermain game online, penurunan prestasi akademik, relasi sosial, dan gangguan kesehatan (Kementerian Kesehatan Republik Indonesia, 2018). Selain itu, bermain game online dengan durasi yang lama dapat berpengaruh pada gangguan kesehatan seperti gangguan tidur, kelelahan secara fisik (pusing, kaku leher, otot, dan sakit punggung), fatigue syndrome, mental disorder, hingga Carpal Tunnel Syndrome (CTS).

Carpal Tunnel Syndrome (CTS) atau sindroma terowongan karpal (STK) merupakan salah satu gangguan pada lengan tangan akibat penyempitan terowongan karpal, baik akibat edema fasia maupun akibat kelainan pada tulang-tulang kecil tangan sehingga terjadi penekanan terhadap nervus medianus (Bahrudin, 2011). Hal tersebut sejalan dengan penelitian yang dilakukan oleh Ayunita (2017), ditemukan bahwa gerakan tangan saat menggunakan keyboard dan mouse dalam bermain game online memiliki tingkat repetisi tinggi pada jari tangan sehingga menimbulkan berbagai keluhan yang berpengaruh terhadap kejadian Carpal Tunnel Syndrome (CTS). Penelitian lain yang dilakukan oleh Efendi (2014) juga menemukan bahwa prevalensi risiko kejadian Carpal Tunnel Syndrome (CTS) pada pemain game online "Mobile Legends: Bang bang" di Kota Padang cukup besar yaitu mencapai angka 75,3\%. Penelitian menemukan adanya hubungan antara postur pergelangan tangan dengan 
risiko kejadian Carpal Tunnel Syndrome (CTS).

Penelitian yang dilakukan oleh Zain et al., (2014) menyatakan bahwa terdapat korelasi antara bermain komputer game dengan kejadian Carpal Tunnel Syndrome (CTS) pada remaja Universitas Malaysia. Penelitian yang dilakukan oleh (Wardana et al., (2018) yang berjudul Faktor-Faktor yang Berhubungan dengan Kejadian Carpal Tunnel Syndrome (CTS) pada Pekerja Unit Assembling PT. X Kota Semarang Tahun 2018 menyatakan bahwa terdapat hubungan usia terhadap kejadian Carpal Tunnel Syndrome (CTS). Namun, penelitian ini tidak sejalan dengan penelitian yang dilakukan oleh Selviyati et al., (2016)(Veni Selviyati, Anita Camelia, 2016) yang berjudul Analisis Determinan Kejadian Carpal Tunnel Syndrome (CTS) pada Petani Penyadap Pohon Karet di Desa Karang Manik Kecamatan Belitang II Kabupaten Oku Timur yang menyatakan bahwa tidak terdapat hubungan antara usia dengan kejadian Carpal Tunnel Syndrome (CTS). Namun, terdapat hubungan antara jenis kelamin dengan kejadian Carpal Tunnel Syndrome (CTS) yaitu pada petani yang berjenis kelamin perempuan mempunyai risiko 0,683 kali lebih besar untuk mengalami kejadian Carpal Tunnel Syndrome (CTS) dibandingkan dengan petani yang berjenis kelamin laki-laki.

Penelitian terkait faktor risiko Carpal Tunnel Syndrome (CTS) pada siswa SMA pemain game online di Kota Denpasar belum dilaksanakan. Sehingga penulis tertarik untuk mengangkat topik penelitian tersebut. Berdasarkan paparan yang telah dijelaskan, maka peneliti tertarik untuk meneliti tentang "Faktor Risiko Carpal Tunnel Syndrome (CTS) pada Siswa SMA Pemain Game Online di Kota Denpasar".

\section{METODE PENELITIAN}

Penelitian ini merupakan penelitian analitik dengan pendekatan kuantitatif. Rancangan penelitian menggunakan metode cross-sectional study untuk menganalisis faktor risiko Carpal Tunnel Syndrome (CTS) pada pemain game online usia remaja di Kota Denpasar.

Populasi terjangkau pada penelitian ini yaitu salah satu Sekolah Menengah Atas (SMA) Negeri di Kota Denpasar dan Sekolah Menengah Atas (SMA) Swasta di Kota Denpasar yang bermain game online. Jumlah sampel pada penelitian adalah 70 responden. Teknik pengambilan sampel menggunakan teknik purposive sampling. Instrumen pengumpulan data yang digunakan dalam penelitian ini yaitu kuesioner mencakup karakteristik individu (usia dan jenis kelamin), pola bermain, jenis permainan, repetitive motion, phalen's test, dan BCTQ (Boston Carpal Tunnel Syndrome Questionaire). Pengumpulan data dimulai dengan penyebaran kuesioner kepada responden yang telah terpilih saat pengambilan sampel secara online melalui google form. Hal ini dilakukan akibat adanya pandemic COVID-19. Kuesioner diawali dengan persetujuan informed consent pada 
responden yang setelah itu dilanjutkan dengan pengisian isi kuesioner.

Data dianalisis melalui tiga tahap yaitu analisis deskriptif, analisis bivariabel dengan uji chi-square dan analisis multivariabel dengan uji multiple logistic regression untuk mengetahui pengaruh murni antar variabel bebas terhadap variabel tergantung.

\section{HASIL}

Berdasarkan Tabel 1, didapatkan hasil bahwa sebagian besar responden berusia lebih dari 16 tahun sebanyak 45 orang $(64,29 \%)$, sedangkan 25 orang lainnya $(35,71 \%)$ berusia kurang dari 16 tahun. Rata-rata (SD) usia responden pada penelitian ini adalah 16.89 tahun $(S D=1,07)$ dengan usia paling muda 15 tahun dan usia paling tua 19 tahun. Sebagian besar responden $(67,14 \%)$ berjenis kelamin lakilaki dengan jumlah 47 orang.

Tabel 1. Karakteristik Responden

\begin{tabular}{lcc}
\hline \multicolumn{1}{c}{$\begin{array}{c}\text { Karakteristik } \\
\text { Responden }\end{array}$} & $\begin{array}{c}\text { Frekuensi } \\
\text { (n) }\end{array}$ & $\begin{array}{c}\text { Proporsi } \\
\text { (\%) }\end{array}$ \\
\hline Usia & & \\
$\leq 16$ tahun & 25 & 35,71 \\
$>16$ tahun & 45 & 64,29 \\
\hline Jenis Kelamin & & \\
Perempuan & 23 & 32,86 \\
Laki-laki & 47 & 67,14 \\
\hline
\end{tabular}

Proporsi Carpal Tunnel Syndrome (CTS) pada penelitian ini, diukur dengan pemeriksaan fisik phalen's test. Pengukuran dilakukan dengan gerakan fleksi tangan responden secara maksimal selama 1 menit. Berdasarkan Tabel 2, sebanyak 48 orang
(68,57\%) menunjukkan negatif dan 22 orang $(31,43 \%)$ lainnya menunjukkan hasil positif. Dari 22 responden yang menunjukkan hasil positif saat phalen's test, sebagian besar merasakan nyeri yaitu sebanyak 17 orang $(77,27 \%)$, selain itu beberapa responden merasakan kesemutan yaitu sebanyak 5 orang $(22,73 \%)$ sedangkan pada gejala mati rasa tidak ada satupun responden yang merasakannya.

Tabel 2. Proporsi CTS pada Responden

$\begin{array}{ccc}\text { Carpal Tunnel } & \text { Frekuensi } & \text { Proporsi } \\ \text { Syndrome } & \text { (n) } & \text { (\%) } \\ \text { (CTS) } & & \end{array}$

\section{Proporsi CTS}

$\begin{array}{lll}\text { Negatif } & 48 & 68,57 \\ \text { Positif } & 22 & 31,43\end{array}$

\section{Gejala yang}

Timbul

$\begin{array}{lcc}\text { Nyeri } & 17 & 77,27 \\ \text { Kesemutan } & 5 & 22,73 \\ \text { Mati rasa } & 0 & 00,00\end{array}$

Responden yang menunjukkan hasil positif saat phalen's test selanjutnya wajib mengisi kuesioner Boston Carpal Tunnel Syndrome Questionare (BCTQ) untuk mengetahui skala keparahan gejala dan skala status fungsional responden. Berdasarkan Tabel 3, skala keparahan gejala paling banyak berada pada kategori ringan $(72,73 \%)$ dengan rata-rata skor mencapai $15,09(\mathrm{SD}=3,91)$, skor minimal 11 dan skor maksimal 24. Pada skala status fungsional, sebagian besar responden memiliki kategori ringan $(77,27 \%)$. Skala status fungsional menunjukkan skor rata-rata mencapai 8,409 
Tabel 3. Gambaran BCTQ

\begin{tabular}{lcc}
\hline \multicolumn{1}{c}{ Gambaran BCTQ } & Frekuensi (n) & Proporsi (\%) \\
\hline Skala Keparahan Gejala & 5 & \\
Tidak ada gejala & 16 & 22,73 \\
Ringan & 1 & 72,73 \\
Sedang & 0 & 4,55 \\
Parah & 0 & 00,00 \\
Sangat parah & & 00,00 \\
Skala Status Fungsional & 5 & \\
Tidak ada kesulitan & 17 & 22,73 \\
Ringan & 0 & 77,27 \\
Sedang & 0 & 00,00 \\
Parah & 0 & 00,00 \\
Sangat parah & 00,00 \\
\hline
\end{tabular}

Pola bermain pada penelitian ini mencakup durasi dan frekuensi bermain pada masing-masing responden. Pola bermain yang digunakan dikelompokkan menjadi 3 kategori yaitu (1) kategori jarang dengan frekuensi bermain 1-2 kali per minggu dengan durasi < 3,5 jam, (2) kategori cukup sering dengan frekuensi bermain 3-5 kali per minggu dengan durasi 3,5 jam-7 jam, dan (3) kategori sering dengan frekuensi bermain 6-8 kali per minggu dengan durasi $>7$ jam.

Berdasarkan Tabel 4, diketahui bahwa sebagian besar responden (47,14\%) tergolong dalam kategori jarang bermain dengan jumlah 33 orang. Selanjutnya, 27 orang responden tergolong dalam kategori cukup sering bermain dengan proporsi $38,57 \%$ dan 10 orang lainnya tergolong dalam kategori terakhir yaitu sering bermain dengan proporsi sebesar 14,29\%.

Tabel 4. Gambaran Pola Bermain

\begin{tabular}{lcc}
\hline $\begin{array}{c}\text { Pola } \\
\text { Bermain }\end{array}$ & Frekuensi (n) & Proporsi (\%) \\
\hline Jarang & 33 & 47,14 \\
$\begin{array}{l}\text { Cukup } \\
\text { sering }\end{array}$ & 27 & 38,57 \\
Sering & 10 & 14,29 \\
\hline
\end{tabular}

Berdasarkan perangkat bermain pada Tabel 5, diketahui sebanyak 53 orang $(75,71 \%)$ responden menggunakan handphone/joystick sebagai sarana bermain game online dan sebanyak 17 orang lainnya (24,29\%) menggunakan komputer.

Berdasarkan jenis permainan, dapat disimpulkan bahwa sebagian besar responden memilih untuk memainkan jenis Massively Multiplayer Online Games. Terlihat 
dari jumlah peminat jenis MMOFPS

sebanyak 26 orang $(37,14 \%)$ disusul dengan

MMORPG dan MMO Browser Game.

Tabel 5. Jenis Permainan \& Perangkat

Jenis Permainan dan Perangkat

Bermain

Frekuensi (n) Proporsi (\%)

\begin{tabular}{lcc}
\hline Jenis Permainan & & \\
Cross-platform Online Play & 7 & 10,00 \\
MMO Browser Games & 6 & 8,57 \\
MMO First-person Shooter Games & 26 & 37,14 \\
MMO Role-playing Games & 20 & 28,57 \\
Simulation Games & 11 & 15,71 \\
Perangkat Bermain & & \\
Handphone/ & 53 & 75,71 \\
Joystick & & \\
Komputer & 17 & 24,29 \\
\hline
\end{tabular}

Berdasarkan Tabel 6, didapatkan

Syndrome diketahui bahwa pada variabel usia dalam karakteristik responden, hasil uji

hasil bahwa sebagian besar responden menyatakan bermain game online dengan gerakan lebih dari 30 kali per menit dengan jumlah 39 orang (55,71\%). Repetitive motion bertujuan untuk mengetahui jumlah gerakan responden per menitnya.

Tabel 6. Gambaran Repetitive Motion

\begin{tabular}{lcc}
\hline $\begin{array}{c}\text { Repetitive } \\
\text { Motion }\end{array}$ & $\begin{array}{c}\text { Frekuensi } \\
\text { (n) }\end{array}$ & $\begin{array}{c}\text { Proporsi } \\
\text { (\%) }\end{array}$ \\
\hline $\begin{array}{l}\text { < } 30 \text { kali per } \\
\text { menit }\end{array}$ & 31 & 44,29 \\
$\geq 30$ kali per & 39 & 55,71 \\
menit & & \\
\hline
\end{tabular}

Uji yang digunakan dalam menghubungkan variabel bebas dengan variabel tergantung adalah uji chi-square. Berdasarkan Tabel 7, yang menjelaskan tentang hubungan CTS atau Carpal Tunnel

chi-square didapatkan bahwa nilai p-value 0,25 dengan PR 0,67 dan CI (0,33-1,31) yang berarti tidak terdapat hubungan antara usia dengan kejadian CTS.

Pada kelompok jenis kelamin, hasil analisis uji chi-square menunjukkan bahwa nilai p-value yang diperoleh adalah 0,50 > 0,05 (tidak signifikan) dengan PR 1,30 dan CI (0,58-2,88). Hal ini dapat disimpulkan bahwa tidak terdapat hubungan antara jenis kelamin dengan kejadian CTS.

Pada pola bermain, hasil analisis menunjukkan bahwa nilai p-value yang diperoleh adalah 0,00<0,05 (signifikan) dengan PR 18,72 dan CI (2,66-131,70). Hal ini dapat disimpulkan bahwa terdapat hubungan antara pola bermain dengan kejadian CTS. 
Pada perangkat bermain, hasil analisis menunjukkan bahwa nilai p-value yang diperoleh adalah 0,00 $<0,05$ (signifikan) dengan nilai PR 5,45 dan CI $(2,77-10,71)$. Hal ini dapat disimpulkan bahwa terdapat hubungan antara perangkat bermain yang digunakan dengan kejadian CTS.

Pada variabel repetitive motion < 30 kali per menit menghasilkan kejadian CTS negatif sebesar $93,55 \%$ pada 29 orang dan 2 orang positif sebesar 6,45\%. Sedangkan, repetitive motion $\geq 30$ kali per menit mencapai $48,72 \%$ negatif pada 19 orang dan $51,28 \%$ positif pada 20 orang. Hasil analisis menunjukkan bahwa nilai p-value yang diperoleh adalah 0,00<0,05 (signifikan) dengan nilai PR 7,94 dan CI (2,00-31,43). Hal ini dapat disimpulkan bahwa terdapat hubungan antara repetitive motion dengan kejadian CTS.

\section{Tabel 7. CTS}

\section{Carpal Tunnel}

\begin{tabular}{|c|c|c|c|c|c|c|}
\hline \multirow{2}{*}{ Variabel } & \multicolumn{2}{|c|}{ Syndrome (CTS) } & \multirow[b]{2}{*}{$\begin{array}{c}\text { Total } \\
\text { Responden }\end{array}$} & \multirow[b]{2}{*}{$\begin{array}{c}\mathrm{P} \\
\text { Value }\end{array}$} & \multirow[b]{2}{*}{ PR } & \multirow[b]{2}{*}{$95 \%$ CI } \\
\hline & $\begin{array}{c}\text { Negatif } \\
\text { n (\%) }\end{array}$ & $\begin{array}{c}\text { Positif } \\
\text { n (\%) }\end{array}$ & & & & \\
\hline \multicolumn{7}{|l|}{ Usia } \\
\hline$\leq 16$ tahun & $15(60,00)$ & $10(40,00)$ & 25 & 0,25 & 0,67 & $(0,33-1,31)$ \\
\hline$>16$ tahun & $33(73,33)$ & $12(26,67)$ & 45 & & & \\
\hline \multicolumn{7}{|l|}{ Jenis Kelamin } \\
\hline Perempuan & $17(73,91)$ & $6(26,09)$ & 23 & 0,50 & 1,30 & $(0,58-2,88)$ \\
\hline Laki-laki & $31(65,96)$ & $16(34,04)$ & 47 & & & \\
\hline \multicolumn{7}{|l|}{ Pola Bermain } \\
\hline Jarang & $32(96,97)$ & $1(3,03)$ & 33 & 0,00 & 18,72 & $(2,66-131,70)$ \\
\hline Cukup Sering & $16(59,26)$ & $11(40,74)$ & 27 & & & \\
\hline Sering & $0(0,00)$ & $10(100,00)$ & 10 & & & \\
\hline \multicolumn{7}{|l|}{ Perangkat } \\
\hline $\begin{array}{l}\text { Handphonel } \\
\text { Joystick }\end{array}$ & $45(84,91)$ & $8(15,09)$ & 53 & 0,00 & 5,45 & $(2,77-10,71)$ \\
\hline Komputer & $3(17,65)$ & $14(82,35)$ & 17 & & & \\
\hline \multicolumn{7}{|l|}{ Repetitive } \\
\hline $\begin{array}{l}<30 \text { kali per } \\
\text { menit }\end{array}$ & $29(93,55)$ & $2(6,45)$ & 31 & 0,00 & 7,94 & $(2,00-31,43)$ \\
\hline $\begin{array}{l}\geq 30 \text { kali per } \\
\text { menit }\end{array}$ & $19(48,72)$ & $20(51,28)$ & 39 & & & \\
\hline
\end{tabular}


Berdasarkan hasil uji bivariat, hanya variabel kategori usia, pola bermain, perangkat, dan repetitive motion yang memiliki nilai $\mathrm{p}<0,25$ sehingga variabel-

variabel ini memenuhi kriteria untuk dimasukkan ke dalam uji multivariat.

Uji yang digunakan adalah multiple logistic regression dengan metode enter. Metode ini biasanya dilakukan untuk studi cross-sectional. Pada hasil uji regresi logistik yang telah dilakukan, nilai $\mathrm{p}$ model secara keseluruhan adalah 0,000<0,05 (signifikan). Hal ini menunjukkan bahwa model secara keseluruhan fit. Berdasarkan Tabel 8, dapat dilihat bahwa faktor risiko pada pemain game online yang paling berpengaruh terhadap CTS adalah pola bermain $(95 \% \mathrm{CI}$ $=2,698-208,996 ; \mathrm{p}=0,004)$ dan perangkat bermain (95\% CI = 1,118 - 65,133; $\mathrm{p}=0,039)$. Berdasarkan hasil analisis multivariabel, faktor yang paling bermakna dalam mempengaruhi kejadian CTS adalah pola bermain. Jika dilihat dari odd ratio, responden dengan pola bermain sering memiliki risiko 23,74 kali untuk terkena CTS dibandingkan dengan responden kategori jarang pada pola bermain.

Tabel 8. Analisis Multivariabel Faktor Risiko CTS

\begin{tabular}{|c|c|c|c|c|}
\hline \multirow{3}{*}{ Variabel } & \multicolumn{3}{|c|}{ Model Akhir } & \multirow{3}{*}{$\mathrm{p}$} \\
\hline & \multirow{2}{*}{$\begin{array}{c}\text { Adjusted } \\
\text { OR }\end{array}$} & \multicolumn{2}{|c|}{ 95\% CI for OR } & \\
\hline & & Lower & Upper & \\
\hline \multicolumn{5}{|l|}{ Usia } \\
\hline$>16$ tahun & 0,33 & 0,057 & 1,958 & 0,224 \\
\hline$\leq 16$ tahun & Reff & & & \\
\hline \multicolumn{5}{|l|}{ Pola Bermain } \\
\hline Sering & 23,74 & 2,698 & 208,996 & 0,004 \\
\hline Jarang & Reff & & & \\
\hline \multicolumn{5}{|l|}{ Perangkat Bermain } \\
\hline Komputer & 8,53 & 1,118 & 65,133 & 0,039 \\
\hline Handphone/Joystick & Reff & & & \\
\hline \multicolumn{5}{|l|}{ Repetitive Motion } \\
\hline$\geq 30$ kali per menit & 5,01 & 0,540 & 46,492 & 0,156 \\
\hline$<30$ kali per menit & Reff & & & \\
\hline
\end{tabular}

\section{DISKUSI}

Hasil penelitian menunjukkan bahwa dari karakteristik usia, rata-rata responden pada penelitian ini berusia 16,89 tahun dengan responden usia termuda adalah 15 tahun dan tertua berusia 19 tahun. Menurut Kementerian Kesehatan Republik Indonesia (2017), remaja adalah penduduk dalam rentang usia 10-19 tahun. Sama halnya 
dengan Badan Kependudukan dan Keluarga Berencana (2019) yang menyatakan bahwa rentang usia remaja adalah 10-24 tahun dan belum menikah. Hal ini sejalan dengan penelitian Nurazmi et al., (2018) bahwa pemain game online didominasi oleh remaja tengah usia 15-19 tahun. Hal ini menunjukkan bahwa yang menjadi responden pada penelitian ini seluruhnya termasuk dalam kategori remaja.

Menurut jenis kelamin, responden dikelompokkan menjadi 2 yaitu responden dengan jenis kelamin perempuan dan lakilaki. Pada penelitian ini didominasi oleh responden laki-laki sebanyak 67,14\% sisanya adalah responden perempuan sebanyak 32,86\%. Penelitian yang dilakukan oleh Putra et al., (2017) menyebutkan siswa laki-laki bermain game cenderung lebih banyak daripada siswa perempuan, dikarenakan terdapat perbedaan pengaruh pada otak laki-laki dan perempuan ketika bermain game yang memicu laki-laki lebih termotivasi dalam menyelesaikan tantangan dalam game yang dapat mengaktifkan kemampuan kognitif. Hal tersebut menjadi dasar bahwa penggemar game lebih dominan pada laki-laki daripada perempuan.

Hasil penelitian menunjukkan 31,43\% responden menunjukkan hasil positif CTS setelah melakukan pengukuran phalen's test dengan $77,27 \%$ responden merasakan nyeri dan 22,73\% responden merasakan kesemutan. Hal ini sejalan dengan penelitian yang dilakukan oleh Putra \&
Ratnawati (2020) yang menyatakan bahwa sebanyak 55\% remaja yang bermain game online positif mengalami CTS dan $45 \%$ negatif mengalami CTS. Hasil dapat dikatakan positif jika responden mengalami gejala kram, kesemutan, dan nyeri pada saat pemeriksaan fisik CTS.

Sebanyak 31,43\% responden yang dinyatakan positif CTS berdasarkan hasil phalen's test, wajib untuk mengisi kuesioner BCTQ. Pada skala keparahan gejala, ratarata skor mencapai 15,09 dengan skor minimal 11 dan skor maksimal 24 sehingga $31,43 \%$ responden termasuk dalam kategori ringan. Pada skala status fungsional, skor rata-rata mencapai 8,409 dengan skala minimal 7 dan skala maksimal 12, sehingga $31,43 \%$ responden termasuk dalam kategori ringan.

Sebanyak 47,14\% responden memilih jarang bermain game, 38,57\% responden cukup sering bermain game, dan 14,29\% responden sering bermain game. Menurut Nurazmi et al., (2018) seseorang dikatakan kecanduan game online jika bermain lebih dari 30 menit dalam sehari. Jika dinilai dari waktu bermain responden dalam penelitian ini dapat disimpulkan bahwa sebagian besar responden kecanduan game online.

Hasil data dalam penelitian ini, menyatakan bahwa $37,14 \%$ responden tertarik dengan permainan jenis MMOFPS. Pada urutan kedua diduduki oleh jenis permainan MMORPG dengan proporsi sebesar 28,57\%, lalu disusul oleh jenis lainnya. Penelitian ini sejalan dengan penelitian yang dilakukan oleh Putra \& 
Ratnawati (2020) bahwa jenis permainan MMOFPS dan MMORPG lebih banyak diminati oleh responden remaja dengan jumlah total 50 responden (50\%). Menurut Surbakti (2017), jenis permainan MMOFPS dan MMORPG merupakan game yang paling terkenal pada tahun 2017 karena dapat dimainkan secara bersama-sama.

Perangkat bermain diklasifikasikan menjadi handphone/joystick dan komputer. Terdapat sebanyak $75,71 \%$ responden menggunakan handphone/joystick sebagai perangkat bermain dan 24,29\% lainnya bermain menggunakan komputer.

Sebanyak $55,71 \%$ responden bermain game dengan gerakan $\geq 30$ kali per menit dan $44,29 \%$ responden lainnya bermain game dengan gerakan $<30$ kali per menit. Menurut Rina (2010) pengulangan yang dilakukan dalam waktu $<30$ detik dapat dikatakan sebagai repetitive motion. Bagian lengan dan tangan yang melakukan repetitive motion $>10$ kali per menit dapat berisiko terhadap CTS.

Berdasarkan nilai PR, 95\% CI dan nilai $\mathrm{p}$ menunjukkan bahwa variabel usia dengan kejadian CTS tidak memiliki hubungan bermakna secara statistik. Penelitian ini sejalan dengan penelitian Kurniawan et al., (2008) yang menyatakan tidak ada hubungan antara usia dengan CTS $(p=1,000)$ dengan hasil bahwa semua pekerja memiliki peluang yang sama terhadap CTS. Hasil ini berbanding terbalik dengan penelitian Basuki et al., (2015) yang menyatakan adanya hubungan antara usia dengan CTS $(p=0,026)$.
Perbedaan hasil dapat disebabkan oleh karakteristik usia responden yang berbeda. Hal ini sesuai dengan teori Seffinger \& Hruby (2007) yang menyatakan bahwa CTS lebih rentan terjadi pada usia 30-80 tahun dan jarang terjadi pada usia $<30$ tahun. Risiko CTS akan meningkat bagi individu seiring bertambahnya usia (Ashworth, 2010). Selain itu, kondisi remaja yang lebih fit dan jenis pekerjaan yang dilakukan tidak sebanyak yang dilakukan oleh usia dewasa juga meminimalisir kemungkinan atau peluang remaja dalam mengidap penyakit CTS.

Dari hasil uji statistik chi-square jenis kelamin didapatkan nilai PR sebesar 1.30 dengan nilai $\mathrm{p}=0,50$ (95\% CI 0,58-2,88). Hal ini menunjukkan bahwa variabel jenis kelamin dengan kejadian CTS tidak signifikan secara statistik. Hal ini sejalan dengan penelitian yang dilakukan oleh Fitriani (2012) bahwa tidak ada hubungan signifikan antara jenis kelamin dengan dugaan CTS. Namun, berbeda dengan penelitian yang dilakukan oleh Mattioli et al., (2008) dan Saleha (2017). Mattioli menyebutkan bahwa perempuan 3,6 kali lebih rentan terhadap CTS daripada lakilaki dan Saleha juga menyebutkan bahwa prevalensi CTS terjadi lebih besar pada wanita daripada laki-laki sebesar 3:1. Hal ini disebabkan oleh anatomi tulang karpal perempuan yang lebih kecil sehingga ruang bergerak saraf dan tendon lebih ketat. Ashworth (2010) juga menjelaskan bahwa laki-laki mengalami CTS secara bertahap dan meningkat sampai usia lanjut, sedangkan perempuan memuncak setelah 
menopause yang secara umum dapat berhubungan dengan konsep komponen hormonal dalam penyebab CTS.

Tidak adanya hubungan antara jenis kelamin dengan CTS pada penelitian ini jika dikaitkan dengan teori sebelumnya mungkin dikarenakan oleh hormon remaja yang masih dalam masa pubertas sehingga sejalan dengan teori Ashworth (2010) yang menyebutkan bahwa kejadian CTS dapat memuncak pada saat perempuan mengalami menopause dan laki-laki memasuki usia lanjut.

Hasil uji statistik chi-square pola bermain didapatkan nilai PR sebesar 18,72 dengan nilai $\mathrm{p}=0,00$ (95\% CI 2,66-131,70). Hal ini menunjukkan bahwa variabel pola bermain dengan kejadian CTS adalah signifikan. Penelitian ini sejalan dengan BBasuki et al., (2015) yang menyatakan bahwa adanya hubungan antara lama kerja tangan dengan kejadian CTS. Pekerjaan yang dilakukan $>4$ jam akan menurunkan produktivitas individu sehingga berpengaruh terhadap CTS. Namun, hal ini tidak sejalan dengan penelitian yang dilakukan oleh Kurniawan et al. (2008) bahwa lama kerja pada tangan tidak selalu berhubungan dengan kejadian CTS. Perbedaan hasil ini kemungkinan disebabkan oleh perbedaan gerakan individu dalam melakukan pekerjaan. Sehingga terdapat individu yang mengalami CTS dalam kurun waktu tertentu adapula yang tidak.

Jumlah responden dengan perangkat komputer lebih banyak mengalami CTS walaupun jumlah keseluruhan responden lebih kecil daripada responden dengan perangkat handphone/joystick. Hasil uji statistik chi-square mendapatkan nilai PR sebesar 5,45 dengan nilai $\mathrm{p}=0,00$ (95\% CI 2,77-10,71) yang menunjukkan bahwa variabel perangkat bermain dengan kejadian CTS adalah signifikan. Menurut Soewardi et al. (2015) mayoritas remaja yang bermain game online menggunakan keyboard dan mouse (perangkat komputer) lebih berpengaruh terhadap kejadian CTS. Menurut Pakasi (2005), hal ini disebabkan oleh penggunaan komputer yang banyak mempengaruhi tangan dalam pergerakan fleksi yang jika terjadi secara terus-menerus dan dibiarkan dapat menyebabkan tekanan pada nervus median.

Uji statistik chi-square repetitive motion didapatkan nilai PR sebesar 7,94 dengan nilai $\mathrm{p}=0,00 \quad(95 \% \quad \mathrm{CI} \quad 2,00-31,43)$ yang menunjukkan bahwa variabel repetitive motion dengan kejadian CTS adalah signifikan. Sejalan dengan Kurniawan et al., (2008) yang menyatakan bahwa terdapat hubungan antara frekuensi gerakan berulang (repetitive motion) dengan CTS pada pemetik melati di Desa Karangcengis. Namun, Nissa et al., (2015) menyatakan bahwa tidak ada hubungan antara gerakan berulang dengan kejadian CTS pada mahasiswa teknik arsitektur Universitas Diponegoro yang disebabkan oleh kecilnya jumlah gerakan per menit yang dihasilkan oleh responden. Perbedaan hasil tersebut kemungkinan disebabkan oleh jumlah gerakan berulang (repetitive motion) yang 
berbeda pada setiap responden berdasarkan pekerjaan atau aktivitas yang dilakukan.

Pada variabel pola bermain yang dihasilkan dalam analisis multivariat, ditemukan bahwa responden dengan pola bermain sering berpotensi 23,74 kali untuk terkena CTS dibandingkan dengan responden kategori pola bermain jarang (OR=23,74; 95\% CI=2,698-208,996; $\mathrm{p}=0,004$ ). Setiawan et al., (2018) berpendapat bahwa seseorang yang melakukan aktivitas secara terus-menerus dalam waktu yang lama dapat mengalami kerusakan pada jaringan lunak dalam terowongan karpal yang biasa disebut penyakit CTS.

Pada variabel perangkat bermain menunjukkan bahwa responden dengan perangkat bermain komputer memiliki risiko 8,53 kali untuk terkena CTS dibandingkan dengan responden yang menggunakan perangkat bermain handphone/joystick (OR=8,53; 95\% CI=1,11865,133; $p=0,039)$. Hal ini sejalan dengan hasil penelitian Eleftheriou et al., (2012) bahwa berdasarkan analisis keeratan variabel paparan penggunaan keyboard dapat meningkatkan risiko CTS dengan nilai $\mathrm{OR}=2,41 \quad$ (95\% $\quad \mathrm{CI}=1,36-4.25 ; \quad \mathrm{p}=0,001)$. Penelitian dari Nafasa et al., (2019) menyebutkan bahwa semakin lama intensitas penggunaan komputer akan menghasilkan gerakan berulang pada tangan secara terus-menerus dan menimbulkan tekanan mekanik sehingga mempersempit jaringan yang berisiko terhadap CTS.

Hasil dari penelitian ini menunjukkan adanya pengaruh pola bermain dan perangkat bermain yang signifikan terhadap kejadian Carpal Tunnel Syndrome (CTS). Hal ini mengindikasikan bahwa siswa yang memiliki intensitas pola bermain tinggi dan perangkat berisiko akan memiliki hasil pemeriksaan phalen's test dengan positif CTS yang lebih tinggi. Hal ini kemungkinan terjadi karena pengaruh negatif dari pola bermain yang tinggi (siswa bermain game online dalam durasi $>7$ jam dengan frekuensi 6-8 x per minggu atau kategori sering) serta penggunaan perangkat bermain secara terus-menerus. Hal tersebut dapat mengganggu fungsional terowongan karpal sehingga menyebabkan CTS.

Hasil penelitian ini secara praktis digunakan sebagai bahan masukan kepada pihak sekolah, siswa, dan orang tua siswa agar lebih memperhatikan kemajuan teknologi terutama terkait dengan pengaksesan game online. Jika dikaitkan dengan program yang sudah ada, seperti program Pemerintah Provinsi Jawa Barat yang telah mendirikan pusat rehabilitasi bagi remaja pecandu game Renaldi (2020) tentunya dapat dijadikan referensi oleh Pemerintah Provinsi Bali untuk memperkecil risiko kasus CTS pada remaja akibat kecanduan game online. Promosi kesehatan juga diperlukan sebagai upaya preventif, misalnya dengan memberikan materi edukasi atau waktu sosialisasi yang lebih intens pada remaja baik di rumah maupun di sekolah.

Terdapat kelemahan pada penelitian ini yaitu penyebaran kuesioner dan pemeriksaan fisik (phalen's test) yang 
dilakukan secara online akibat pandemic COVID-19 menyebabkan tidak adanya pengawasan pengisian kuesioner pada responden sehingga data yang didapatkan kemungkinan tidak sesuai dengan kenyataan dan kondisi responden (bias). Namun, data yang peneliti telah cantumkan adalah hasil murni dari pengisian kuesioner responden serta penelitian mengenai CTS pada pemain game online yang mencakup pengukuran pola bermain, jenis permainan, perangkat bermain, dan repetitive motion secara bersamaan masih jarang dilakukan sebelumnya, sehingga membuat peneliti sulit untuk mendapatkan literature yang lengkap dalam menunjang penelitian ini. Hasil yang disajikan peneliti adalah data terbaik yang dapat peneliti kumpulkan.

\section{SIMPULAN}

Berdasarkan pemaparan hasil, dapat disimpulkan bahwa pada penelitian ini sebagian besar responden berusia $>16$ tahun dan dominan berjenis kelamin laki-laki. Dilihat dari pola bermain, sebagian besar responden tergolong dalam kategori jarang dan dominan memilih Massively Miltiplayer Online First-person Shooter Games (MMOFPS) untuk kategori jenis permainan yang dimainkan dengan menggunakan handphone/joystick sebagai perangkat bermain. Pada saat bermain, sebagian besar responden menghasilkan gerakan berulang (repetitive motion) $\geq 30$ kali per menit.

Proporsi CTS pada siswa pemain game online adalah sebesar $31,43 \%$ dengan keluhan gejala nyeri sebesar $77,27 \%$.
Berdasarkan skala keparahan gejala, sebagian besar responden yang telah dinyatakan CTS tergolong dalam kategori keparahan ringan dengan skor 16 (72,73\%) dan pada skala status fungsional terdapat sebanyak $77,27 \%$ responden tergolong dalam kategori gangguan fungsional ringan dengan skor 17 .

Seluruh variabel karakteristik individu yang mencakup usia $(p=0,25)$ dan jenis kelamin $(p=0,50)$ tidak memiliki hubungan yang bermakna dengan kejadian Carpal Tunnel Syndrome (CTS). Variabel pola bermain $(p=0,00)$, perangkat bermain $(\mathrm{p}=0,00)$, dan repetitive motion $(\mathrm{p}=0,00)$ terbukti memiliki hubungan bermakna dengan kejadian Carpal Tunnel Syndrome (CTS).

Pola bermain merupakan faktor risiko yang paling berpengaruh terhadap kejadian Carpal Tunnel Syndrome (CTS) pada siswa pemain game online dengan $\mathrm{OR}=$ 23,74 .

\section{SARAN}

Berdasarkan hasil pada penelitain yang telah dilakukan, maka saran yang dapat peneliti berikan adalah bagi Dinas Kesehatan Kota Denpasar yaitu diharapkan dapat membangun program promosi kesehatan berbentuk preventif yang menyasar pada remaja pemain game online serta orang tua guna mengedukasi lebih intens perihal game online. Materi yang disampaikan dapat berupa dampak beserta upaya pencegahan kecanduan game online; metode 20-20-20; sikap kerja yang baik; dan 
perbaikan stasiun kerja. Penyampaian materi dapat dikemas dalam program menarik sehingga dapat memikat perhatian remaja. Hal ini dilakukan mengingat kecanduan game online telah diklasifikasikan menjadi International Classification of Diseases (ICD-11) sebagai salah satu penyakit mental terbaru menurut WHO (2018), ada baiknya pengguna game maupun orang disekitarnya teredukasi terkait hal tersebut serta membangun program rehabilitatif yang menyasar pada remaja pemain game online. Salah satu program yang dapat dijadikan referensi dalam pembuatan kebijakan baru adalah program milik Pemerintah Provinsi Jawa Barat yaitu pembangunan pusat rehabilitasi remaja pecandu game online.

Siswa diharapkan lebih peduli dengan risiko dan meningkatkan kesadaran dalam memberikan batasan waktu saat bermain game online agar tidak hanya memenuhi kesenangan semata, namun juga menyadari dampak bermain game online pada sisi kesehatan; hendaknya siswa melakukan peregangan atau stretching pada area telapak tangan dengan gerakan keatas $80^{\circ}$ dan gerakan kebawah membentuk sudut $90^{\circ}$ selama \pm 5 menit untuk mengurangi rasa lelah pada area tangan; melakukan peregangan pada bahu seperti mengangkat kedua bahu mendekati telinga lalu tahan dan ulangi beberapa kali serta menggerakkan bahu secara melingkar pada satu arah dan sebaliknya serta peregangan pada bagian punggung belakang jika stasiun kerja yang digunakan saat bermain game online tidak sesuai dengan kaidah ergonomi. Contohnya dengan menarik punggung menggunakan siku (siku posisi aduksi dengan punggung) setelah itu bentangkan tangan seperti gerakan merangkul tubuh; menerapkan metode 2020-20 pada saat bermain game online melalui perangkat komputer ataupun handphone untuk mengurangi kelelahan pada mata. Contohnya dengan 20 menit beraktivitas melihat layar - 20 detik istirahat (dilakukan dengan mengejapkan mata) - menatap obyek sejauh 20 kaki (untuk memfokuskan pandangan mata kembali); perbanyak aktivitas fisik seperti olahraga, di rumah ataupun di luar rumah dengan tetap menerapkan protokol kesehatan era new normal.

Bagi orang tua siswa pemain game online diharapkan dapat menyediakan fasilitas untuk melakukan aktivitas positif seperti memberikan alat-alat untuk melukis ataupun keterampilan lainnya sesuai dengan tren. Remaja akan lebih tertarik dan cenderung ingin tahu pada hal yang berbau tren; melakukan aktivitas fisik seperti olahraga bersama saat pagi atau sore hari; sesekali ajak untuk bermain permainan tradisional untuk mengalihkan penggunaan gadget sekaligus melestarikan budaya; meletakkan perangkat bermain pada ruang terbuka seperti ruang tamu agar mudah dijangkau oleh orang tua; menyediakan stasiun kerja perangkat bermain yang ergonomis. Contohnya seperti memposisikan perangkat yang sesuai disertai dengan pencahayaan yang baik; mendaftarkan siswa dalam aplikasi belajar online sehingga kebutuhan gadget lebih 
bermanfaat, tidak hanya digunakan untuk mengakses game online; sebaiknya tidak melarang siswa dalam bermain, namun lebih kepada melakukan pengawasan terhadap perilaku bermain agar siswa tidak menyaring hal-hal buruk dalam dunia game, karena pada usia remaja ini mereka telah dapat membagi waktu untuk belajar dan bermain; mengajarkan metode 20-20-20 pada saat bermain game online yaitu 20 menit beraktivitas melihat layar - 20 detik istirahat (dilakukan dengan mengejapkan mata) - menatap obyek sejauh 20 kaki (untuk memfokuskan pandangan mata kembali).

Selain variabel pola bermain, jenis permainan, perangkat bermain, dan repetitive motion yang telah diteliti dalam penelitian ini, diharapkan peneliti selanjutnya dapat menggali lebih dalam terkait variabel postur tangan dengan metode pemeriksaan fisik yang lebih objektif dan akurat serta dilakukan pengukuran secara langsung untuk mendapatkan hasil pengukuran Carpal Tunnel Syndrome (CTS) yang lebih tepat dan komprehensif; selain itu dapat menganalisis lebaih dalam terkait perangkat bermain dan membahas lebih banyak terkait perbaikan stasiun kerja dan sikap tubuh yang ergonomi saat bermain game online.

\section{DAFTAR PUSTAKA}

APJII (2019) 'Edisi 40: Laporan Survei Penetrasi \& Profil Perilaku Pengguna Internet Indonesia (Survei 2018)', Bulletin APJII, pp. 1-6.
Ashworth, N. (2010) 'Carpal Tunnel Syndrome (Musculoskeletal Disorders)', BMJ Clinical Evidence Publishing Group, 03(1114), pp. 1-28. Ayunita, D. (2017) 'Pengaruh Penambahan Tendon and Nerve Gliding Exercise pada Ultrasound Terhadap Penurunan Nyeri Carpal Tunnel Sydrome', Jurnal Publikasi Fisioterapi, 1(3), pp. 1-14.

Badan Kependudukan dan Keluarga Berencana (2019) Kalau Terencana Lebih Indah, Siaran Pers No.RILIS/45/B4/BKKBN/VII/2019.

Bahrudin, M. (2011) 'Carpal Tunnel Syndrome (CTS)', Saintika Medika: Jurnal Ilmu Kesehatan dan Kedokteran Keluarga, 7(1), pp. 79-87.

Basuki, R., Jenie, N. and Fikri, Z. (2015) 'Faktor Prediktor Carpal Tunnel Syndrome (CTS) pada Pengerajin Alat Tenun Bukan Mesin (ATBM)', Jurnal Kedokteran Muhammadiyah, 4(1), pp. $1-7$.

Efendi, N. A. (2014) 'Faktor Penyebab Bermain Game Online dan Dampak Negatifnya Bagi Pelajar', Jurnal Ilmiah Kesehatan, 1(2), pp. 1-9.

Eleftheriou, A. et al. (2012) 'Cumulative Keyboard Strokes: A Possible Risk Factor for Carpal Tunnel Syndrome', Journal of Occupational Medicine and Toxicology, 7(16), pp. 1-7.

Eskasasnanda, I. D. P. (2017) 'Causes and Effects of Online Video Game Playing among Junior-Senior High School Students in Malang East Java', 
Komunitas: International Journal of Indonesian Society and Culture, 9(2), pp. 191-202. doi: 10.15294/komunitas.v9i2.9565.

Fajri, C. (2012) 'Tantangan Industri KreatifGame Online di Indonesia', Jurnal ASPIKOM, 1(5), p. 443 . doi: 10.24329/aspikom.v1i5.47.

Fitriani, R. (2012) Faktor-faktor yang Berhubungan dengan Carpal Tunnel Syndrome (CTS) pada Operator Komputer Bagian Sekretariat di Inspektorat Jenderal Kementrian Pekerjaan Umum Tahun 2012. Universitas Islam Negeri Syarif Hidayatullah.

Jordan, C. J. and Andersen, S. L. (2017) 'Sensitive Periods of Substance Abuse: Early Risk for The Transition to Dependence', Developmental Cognitive Neuroscience. Elsevier Ltd, 25(2), pp. 29-44. doi: 10.1016/j.den.2016.10.004.

Kementerian Kesehatan Republik Indonesia (2017) Situasi Kesehatan Reproduksi Remaja. Jakarta Selatan: Pusat Data dan Informasi.

Kementerian Kesehatan Republik Indonesia (2018) Inilah Dampak Kecanduan Game Online, Redaksi Sehat Negeriku. (Accessed: 15 February 2020).

Kurniawan, B., Jayanti, S. and Setyaningsih, Y. (2008) 'Faktor Risiko Kejadian Carpal Tunnel Syndrome (CTS) pada Wanita Pemetik Melati di Desa Karangcecis, Purbalingga', Jurnal Promosi Kesehatan Indonesia, 3(1), pp. 31-37. doi: https://doi.org/10.14710/jpki.3.1.31-37. Kusumawardani, S. P. (2015) 'Game Online Sebagai Pola Perilaku (Studi Deskriptif Tentang Interaksi Sosial Gamers Clash Of Clans Pada Clan Indo Spirit)', Antropologi Universitas Airlangga, 4(2), pp. 154-163. doi: 10.1145/1137677.1137679.

Mattioli, S. et al. (2008) 'Incidence Rates in Hospital - Carpal Tunnel Syndrome in General Population and Possible Associations with Marital Status', BMS Public health, 8(374), pp. 1-10. doi: 10.1186/1471-2458-8-374.

Nafasa, K. et al. (2019) 'Hubungan Masa Kerja dengan Keluhan Carpal Tunnel Syndrome pada Karyawan Pengguna Komputer di Bank BJB Cabang Subang', Jurnal Integrasi Kesehatan \& Sains (JIKS), 1(1), pp. 40-44.

Ngafifi, M. (2014) ‘Kemajuan Teknologi Dan Pola Hidup Manusia Dalam Perspektif Sosial Budaya', Jurnal Pembangunan Pendidikan: Fondasi dan Aplikasi, 2(1), pp. 33-47. doi: 10.21831/jppfa.v2i1.2616.

Nissa, P., Widjasena, B. and Suroto (2015) 'Hubungan Gerakan Repetitif dan Lama Kerja dengan Keluhan Carpal Tunnel Syndrome pada Mahasiswa Teknik Arsitektur', Jurnal Kesehatan Masyarakat, 3(3), pp. 564-571.

Nurazmi, A., Elita, V. and Dewi, W. (2018) 'Hubungan Kecanduan Bermain Game Online Terhadap Regulasi Emosi pada Remaja', Jurnal Online Mahasiswa, Perpustakaan Fakultas 
Keperawatan, 5(2), pp. 555-562.

Oblinger, D. and Oblinger, J. (2005)

Educating the Net Generation. Edited by Oblinger. Educause E-book.

Pakasi, R. (2005) Nyeri dan Kebas Pergelangan tangan Akibat

Pekerjaan? Hati-hati CTS, Medica Store.

Putra, H. and Ratnawati, D. (2020) 'Hubungan Perilaku Bermain Game Online dengan Carpal Tunnel Syndrome Pada Remaja', Fakultas Ilmu Kesehatan, Universitas Pembangunan Nasional Veteran Jakarta, 2(1), pp. 1-12.

Putra, K., Sanubari, T. and Manggena, T. (2017) 'Pengaruh Intensitas Bermain Game Terhadap Tingkat Kognitif (Kecerdasan Logika-Matematika) Usia 8-9 Tahun', Satya Widya, 33(2), pp. 146-153. doi: https://doi.org/10.24246/j.sw.2017.v33. i2.p146-153.

Renaldi, A. (2020) 'Perjuangan Bocah-bocah Indonesia yang Ingin Sembuh dari Kecanduan Game Online', VICE, 27 February, p. 1.

Rina, T. (2010) Hubungan Repetitive Motion dengan Keluhan Carpal Tunnel Syndrome pada Pekerjaan menjahit di Bagian Konveksi I PT. Dan liris Sukoharjo. Universitas Sebelas Maret.

Saleha, R. N. (2017) Proporsi dan Faktor Risiko Kejadian Carpal Tunnel Syndrome (CTS) Pada Pekerja Buruh Cuci di Daerah Plaju Palembang, Fakultas Kedokteran. Universitas
Muhammadiyah Palembang.

Seffinger, M. and Hruby, R. (2007) 'Evidence-based Manual Medicine: A Problem-oriented Approach ClinicalKey 2012', in Couchman, R. (ed.) 1st editio. Philadelphia: Saunders Elsevier, p. 273.

Setiawan, M., Winaya, N. and Muliarta, M. (2018) 'Hubungan Posisi Pergelangan Tangan Saat Mengetik Terhadap Risiko Terjadinya Carpal Tunnel Syndrome (CTS) pada Karyawan PT.X', Majalah Ilmiah Fisioterapi Indonesia, 5(3), pp. 40-43.

Soewardi, H., Anugraheni, A. and Shabrina, N. (2015) 'Analysis of Electromyography on Computer Interaction Devices to the Risk of Carpal Tunnel Syndrome', Yogyakarta, Indonesia, 1(1), pp. 1-7. doi: 10.17706.

Surbakti, K. (2017) 'Pengaruh Game Online Terhadap Remaja', Jurnal Curere, 01(01), pp. 27-38.

Veni Selviyati, Anita Camelia, E. S. (2016) 'Analisis Determinan Kejadian Carpal Tunnel Syndrome (CTS) Pada Petani Penyadap Pohon Karet di Desa Karang Manik Kecamatan Belitang II Kabupaten Oku Timur', Jurnal Ilmu Kesehatan Masyarakat, 7(1), pp. 198208.

Wardana, E. R., Jayanti Siswi and Ekawati (2018) 'Faktor-Faktor Yang Berhubungan Dengan Kejadian Carpal Tunnel Syndrome (Cts) Pada Pekerja Unit Assembling Pt X Kota 
Semarang Tahun 2018.', Jurnal Kesehatan Masyarakat (e-Journal), 6(5), pp. 502-509.

WHO (2018) Gaming Disorder, WHO Team. Available at: https://www.who.int/news-room/q-adetail/gaming-disorder (Accessed: 4 June 2020).
Zain, N. H. M., Jaafar, A. and Razak, F. H. A. (2014) 'Severity scoring of symptoms associated with carpal tunnel syndrome based on recall of computer game playing experiences' Journal of Theoretical and Applied Information Technology, 63(1), pp. 125-135. 